\title{
Clinical Application of Dietary Therapies in Irritable Bowel Syndrome
}

\author{
Anupam Rej ${ }^{1}$, Amanda Avery ${ }^{2}$, Alexander Charles Ford ${ }^{3}$, Anne Holdoway ${ }^{4}$, Matthew Kurien ${ }^{1,5}$, Yvonne McKenzie ${ }^{6}$, Julie \\ Thompson $^{7}$, Nick Trott ${ }^{1}$, Kevin Whelan ${ }^{8}$, Marianne Williamss, David Surendran Sanders ${ }^{1,5}$
}

1) Academic Unit of

Gastroenterology, Royal

Hallamshire Hospital,

Sheffield Teaching Hospital

NHS Foundation Trust,

Sheffield; 2) Division of

Nutritional Sciences, School

of Biosciences, University of

Nottingham, Nottingham;

3) Leeds Institute of

Biomedical and Clinical

Sciences, Leeds University,

Leeds; 4) Registered dietitian,

Bath, Somerset; 5) Academic

Unit of Gastroenterology,

Department of Infection,

Immunity and Cardiovascular

Disease, University of

Sheffield, Sheffield; 6) Nuffield

Health, The Manor Hospital,

Oxford; 7) Calm Gut Clinic,

Todmorden; 8) Department

of Nutritional Sciences, King's

College London, London;

9) Specialist Gastroenterology

Community Dietetic Service,

Somerset Partnership NHS

Foundation Trust, Bridgwater,

United Kingdom

Address for correspondence:

Dr. Anupam Rej

Academic Unit of

Gastroenterology, Royal

Hallamshire Hospital, Sheffield

Teaching Hospital NHS

Foundation Trust, Sheffield,

S10 2JF, UK

anupam.rej@sth.nhs.uk

Received: 26.07.2018

Accepted: 10.08 .2018

\section{ABSTRACT}

Background \& Aims: Diet appears to play a pivotal role in symptom generation in Irritable Bowel Syndrome (IBS). First line dietary therapy for IBS has focused on advice concerning healthy eating and lifestyle management. Research recently has focused on the role of a diet low in fermentable oligo-, di-, and monosaccharides and polyols (FODMAPs), gluten free (GFD) and wheat free (WFD) diets for the relief of symptoms in IBS.

Methods: A round table discussion with gastroenterologists and dietitians with a specialist interest in dietary therapies in IBS was held in Sheffield, United Kingdom in May 2017. Existing literature was reviewed. PubMed and EMBASE were searched with the MeSH terms irritable bowel syndrome/diet/diet therapy/gluten/low FODMAP in different combinations to identify relevant articles. A consensus on the application of these dietary therapies into day-to-day practice was developed.

Results: Fourteen randomized trials in IBS evaluating the low FODMAP diet ( $\mathrm{n}$ studies $=9$ ), GFD $(\mathrm{n}=4$ ) and WFD $(n=1)$ were included in this review. The total number of patients recruited from randomized trials reviewed was: $\mathrm{n}=580$ low FODMAP diet (female, $\mathrm{n}=430$ ), $\mathrm{n}=203$ GFD (female, $\mathrm{n}=139$ ), $\mathrm{n}=276$ WFD (female, $n=215)$. There was no significant difference in the gender of patients recruited for both the low FODMAP and GFD randomized studies $(\mathrm{p}=0.12)$. The response rate in the literature to a low FODMAP diet ranged between 50-76\%, and to GFD ranged between 34-71\%. Percentage of IBS patients identified as wheat sensitive was reported as $30 \%$ in the literature.

Conclusion: There are no head-to-head trials to date utilizing the low FODMAP diet, GFD and WFD for dietary treatment of IBS and still a number of concerns for diets, including nutritional inadequacy and alteration of the gut microbiota. The consensus suggests that there is evidence for the use of the low FODMAP diet, GFD and WFD as dietary therapies for IBS; the decision-making process for using each individual therapy should be directed by a detailed history by the dietitian, involving the patient in the process.

Key words: irritable bowel syndrome - low FODMAP diet - wheat free diet - gluten free diet.

Abbreviations: BDA: British Dietetic Association; FODMAPs: fermentable oligo-, di-, and mono-saccharides and polyols; GFD: gluten free diet; IBS: Irritable Bowel Syndrome (IBS); NICE: National Institute of Clinical Excellence; RCT: Randomized Controlled Trials; VAS: visual analogue scale; WFD: wheat free diet.

\section{INTRODUCTION}

Irritable bowel syndrome (IBS) is common, with a reported global prevalence of approximately $11 \%$, and a female preponderance [1]. The diagnosis is made by clinical features, using the updated Rome IV criteria [2], to subcategorize into diarrhoea-predominant
(IBS-D), constipation-predominant (IBS-C), mixed pattern (IBS-M) and unclassified (IBS-U). There are a number of pathophysiological abnormalities proposed in IBS, including visceral hypersensitivity, altered gut motility, visceral hyperalgesia, genetic and psychological factors [3]. The impact of IBS is substantial, with a reduction in the quality of life, increased use of healthcare and increased time off work [4]. It is therefore paramount that effective therapies are available to manage patients with the disorder.

Diet appears to play a pivotal role in symptom generation in IBS, with approximately two thirds of patients developing 
symptoms soon after the ingestion of food [5-7]. Historically, there has been a great interest in the role of food and induction of IBS symptoms. Food intolerances have been suggested as a precipitating factor in the pathogenesis of IBS for more than 30 years [8], with exclusion and elimination diets leading to symptom improvement in selected patients with IBS. Despite promise being shown from these diets [9], there have been concerns historically about the validity of the data obtained, highlighted by a systematic review of eight studies, demonstrating poor patient selection, inadequate study designs, poor adherence and inappropriate exclusion diets [10]. The historical 'lamb, rice, and pears' diet used in patients with IBS in the 1980s was considered to be highly restrictive and the initial work could not be replicated with the same level of success in other centers $[10,11]$.

Over the last decade, there has been renewed interest in the role of dietary therapies in IBS. First-line dietary management of IBS, as highlighted by the British Dietetic Association (BDA) [12] and National Institute of Clinical Excellence (NICE) [13] has focused on advice concerning healthy eating and lifestyle management. Research recently has focused on the role of a diet low in fermentable oligo-, di-, and mono-saccharides and polyols (FODMAPs) (first study 2006 [14]), wheat free (WFD) (first study 2012 [15]) and gluten free diets (GFD) (first study 2001 [16]) for the relief of symptoms in IBS. There are a number of unanswered questions about the clinical application of the low FODMAP diet, WFD and GFD in IBS, leading to the process described in this article, which we hope can be used as a practical guide for the implementation of these dietary therapies in IBS for all health care professionals.

\section{Format for the Roundtable Discussion}

A roundtable discussion with gastroenterologists and dietitians with a specialist interest in dietary therapies in IBS was held in Sheffield, United Kingdom in May 2017. The following areas were discussed, and used to formulate this review: a brief overview of first-line dietary therapies in IBS; a review of existing literature of low FODMAP, WFD and GFD with an update on recent developments. PubMed and EMBASE were used with the MeSH terms irritable bowel syndrome/diet/ diet therapy/gluten/low FODMAP in different combinations to identify relevant studies; the concerns and unanswered questions in the literature and from clinical practice, and a Consensus on the application of these dietary therapies into clinical practice.

\section{First-line Dietary Therapies}

The BDA [12] and NICE [13] recommend dietary and lifestyle changes as first-line management for IBS. The BDA created an updated set of evidence-based practice guidelines for the dietary management of IBS in 2016 [12]. From the included studies reviewed and evidence statements created, the practical considerations from the BDA included assessing alcohol intake, assessing caffeine intake, assessing other components of spicy meals which may contribute to symptoms, as well as a decrease in fat intake in patients with IBS, with the evidence statements for these interventions being Grade $\mathrm{C}$ evidence. No studies met the criteria for the systematic review of fluid intake due to a lack of evidence, but a gradual increase in fluid intake is recommended by the BDA as a practical consideration. There was inadequate evidence of dietary habits being associated with IBS symptoms (Grade D evidence), but a healthy balanced diet with regular meal patterns has been proposed as a practical consideration [12].

Restriction of milk and dairy products was also reviewed in the updated BDA guidelines, with the practical consideration of lactose restriction to be considered as part of a low FODMAP diet rather than in isolation, with lactose restriction in isolation only providing marginal symptom benefit. There was no highquality evidence that a milk-free diet improves IBS symptoms, with cow's milk protein elimination in atopic individuals being advised to be conducted by allergy-experienced dietitians only [12].

Evidence statements have also been made by the BDA with regards to fibre (Grade $\mathrm{C}$ evidence) - wheat bran fibre, as well as increasing dietary fibre from cereals and fruits have failed to demonstrate symptom improvement in IBS. Ground linseeds relieved constipation, abdominal discomfort and bloating in IBS-C. Ground and whole linseeds as a dietary supplement in IBS are well tolerated, although the evidence on effectiveness is conflicting. The evidence for dietary supplementation of psyllium husk to improve symptoms in IBS and IBS-C is insufficient [12], although a systematic review and metaanalysis, not included in the BDA guidelines, demonstrated empirical evidence for its use [17].

Quality standards for the dietary management of IBS have been outlined by NICE [13]. These include general lifestyle and dietary advice, including increased activity levels, relaxation time, regular meals, increased fluid intake, limiting caffeine and alcohol, less than three portions of fresh fruit a day, avoiding sorbitol and adjustments to fibre [13].

As seen from above, first-line dietary management in IBS includes lifestyle modification, fibre modification, assessment of alcohol, caffeine, fat, fluid and spicy food intake, as well as checking for milk/lactose intolerance. The level of evidence for these interventions has been graded as level C or D, depending on the dietary therapy, by the BDA [12].

\section{THE LOW FODMAP DIET}

A low FODMAP diet has been recommended as a dietary therapy that can be used in the management of IBS $[12,13]$. FODMAPs are short-chain carbohydrates that are poorly absorbed, osmotically active, and increase small bowel water content and intestinal transit [18]. These substances are also fermented in the large bowel, leading to intestinal gas production and distension [19]. Both healthy individuals and patients with IBS have similar luminal distension following fructans, as demonstrated by MRI imaging [20]. However, patients with IBS may have increased visceral hypersensitivity, which is likely the pathophysiological mechanism in symptom generation [19]. The implementation of a low FODMAP diet can be via the 'top-down' or 'bottom-up' approach. The 'top-down' approach involves a strict reduction initially of all FODMAP groups for 4 to 8 weeks, with 4 weeks being generally the time frame recommended for clinical practice [21]. This is followed by a period of FODMAP re-introduction, where if symptoms have improved on a strict low FODMAP diet, 
specific FODMAP triggers and doses that generate symptoms are identified. The final phase is FODMAP personalization, where a less restrictive diet is followed, where FODMAPs which induce symptoms are excluded in addition to a varied and nutritionally adequate dietary intake [21]. The 'bottomup' approach involves the reduction of a few targeted FODMAPs, or reduction of a few foods which contain a very high FODMAP content for 4-8 weeks, followed by further restrictions of FODMAPs only if required [22].

The potential benefits of a low FODMAP diet were hypothesized by Gibson et al. at Monash University, Australia [23]. This was followed by the group focusing on the effect of implementing a low FODMAP diet in IBS [24]. The group initially set out to evaluate an effective dietary therapy in patients with fructose malabsorption and IBS. In this retrospective study, 62 patients presenting consecutively with IBS and fructose malabsorption underwent dietary instruction, comprising avoidance of substantial free fructose and short -chain fructans, as well as total dietary fructose load. Glucose was also balanced with free fructose, as in the presence of luminal glucose, fructose absorption is markedly enhanced. Adherence and effect on abdominal symptoms was assessed via telephone interview, with a positive response to abdominal symptoms being identified in those adherent to the diet versus those non-adherent ( $85 \%$ vs $36 \%, \mathrm{p}<0.01$ ) [14]. The same group subsequently conducted a double-blind placebo-controlled re-challenge trial in 26 patients with IBS and fructose malabsorption, recruited over a 5-month period from a hospital based dietetic practice. Patients were provided all food, low in free fructose and fructans, with random graded introductions of fructose, fructans, alone or in combination, or glucose. Patients receiving fructose, fructans or a combination noted symptoms of IBS were not adequately controlled in comparison with those receiving glucose $(\mathrm{p}<0.002)$. This study demonstrated that the dietary fructose or fructans was likely to be responsible for symptom generation in IBS [25].

Since these initial results, there have been several studies assessing the role of a low FODMAP diet in IBS. Feeding studies, often seen as the gold standard in dietary intervention trials, have shown symptom improvement in patients receiving

Table I. Summary of Randomized Controlled Trials (RCTs) investigating the effect of the low FODMAP diet in patients with IBS ( $\mathrm{n}=580$ )

\begin{tabular}{|c|c|c|c|c|c|c|}
\hline $\begin{array}{l}\text { Lead Author for } \\
\text { Study }\end{array}$ & Year & Study Design & $\begin{array}{l}\text { Study } \\
\text { Duration }\end{array}$ & $\begin{array}{l}\text { Total number of } \\
\text { patients in study }\end{array}$ & Intervention & Outcome \\
\hline Staudacher [28] & 2012 & $\begin{array}{l}\text { Unblinded } \\
\text { RCT }\end{array}$ & 4 weeks & $\begin{array}{l}41 \text { patients with } \\
\text { IBS }\end{array}$ & $\begin{array}{l}\text { Habitual diet } n=22 \\
\text { Low FODMAP diet } n=19\end{array}$ & $\begin{array}{l}\text { Greater adequate control of GI symptoms } \\
\text { on patients with low FODMAP diet } \\
(13 / 19) \text { vs habitual }(5 / 22)(\mathrm{p}=0.005)\end{array}$ \\
\hline Pedersen [29] & 2014 & $\begin{array}{l}\text { Unblinded } \\
\text { RCT }\end{array}$ & 6 weeks & $\begin{array}{l}123 \text { patients with } \\
\text { IBS }\end{array}$ & $\begin{array}{l}\text { Low FODMAP diet } n=42 \\
\text { Lactobacillus rhamnosus GG } \\
\text { diet (probiotic) } n=41 \\
\text { Normal diet (Danish) } n=40\end{array}$ & $\begin{array}{l}\text { Reduction in IBS-SSS in low FODMAP } \\
\text { diet in comparison to Danish diet (IBS- } \\
\text { SSS } 75, \mathrm{p}<0.01 \text { ) }\end{array}$ \\
\hline Halmos [26] & 2014 & $\begin{array}{l}\text { Single blind } \\
\text { crossover RCT }\end{array}$ & 21 days & $\begin{array}{l}30 \text { patients with } \\
\text { IBS and } 8 \text { healthy } \\
\text { individuals }\end{array}$ & $\begin{array}{l}\text { All participants received } \\
\text { diet low in FODMAPs and } \\
\text { Australian diet }\end{array}$ & $\begin{array}{l}\text { Reduction in overall gastrointestinal } \\
\text { symptom score on low FODMAP diet vs } \\
\text { Australian diet }(22.8 \text { vs } 44.9, \mathrm{p}<0.001)\end{array}$ \\
\hline Bohn [30] & 2015 & $\begin{array}{l}\text { Single blind } \\
\text { RCT }\end{array}$ & 4 weeks & $\begin{array}{l}75 \text { patients with } \\
\text { IBS }\end{array}$ & $\begin{array}{l}\text { Low FODMAP diet } \mathrm{n}=38 \\
\text { Traditional dietary advice } \\
\mathrm{n}=37\end{array}$ & $\begin{array}{l}\text { No difference between low FODMAP diet } \\
\text { and traditional diet }(p=0.62)\end{array}$ \\
\hline McIntosh [32] & 2017 & $\begin{array}{l}\text { Single blind } \\
\text { RCT }\end{array}$ & 3 weeks & $\begin{array}{l}37 \text { patients with } \\
\text { IBS }\end{array}$ & $\begin{array}{l}\text { Low FODMAP diet } n=19 \\
\text { High FODMAP diet } n=18\end{array}$ & $\begin{array}{l}\text { Significant difference between proportion } \\
\text { of patients defined as responders (IBS } \\
\text { symptom reduction }>50) \text { between low } \\
\text { FODMAP group vs high FODMAP group } \\
(\mathrm{p}=0.01)\end{array}$ \\
\hline Staudacher [33] & 2017 & $\begin{array}{l}\text { Single blind } \\
\text { RCT }\end{array}$ & 4 weeks & $\begin{array}{l}104 \text { patients with } \\
\text { IBS }\end{array}$ & $\begin{array}{l}\text { Sham diet/placebo } n=27 \\
\text { Sham diet/probiotic } n=26 \\
\text { Low FODMAP diet/placebo } \\
n=24 \\
\text { Low FODMAP diet/probiotic } \\
n=27\end{array}$ & $\begin{array}{l}\text { Significantly lower IBS-SSS in patients on } \\
\text { low FODMAP diet vs sham diet }(p=0.001)\end{array}$ \\
\hline Harvie [34] & 2017 & $\begin{array}{l}\text { Unblinded } \\
\text { RCT }\end{array}$ & 6 months & $\begin{array}{l}50 \text { patients with } \\
\text { IBS }\end{array}$ & $\begin{array}{l}\text { Low FODMAP diet } n=23 \\
\text { Normal diet } n=27 \text { initially } \\
\text { FODMAP re-challenged in } \\
\text { low } \\
\text { FODMAP diet at } 3 \text { months, } \\
\text { crossover to low FODMAP } \\
\text { diet at } 3 \text { months in baseline } \\
\text { diet group }\end{array}$ & $\begin{array}{l}\text { Reduction in IBS-SSS on low FODMAP } \\
\text { diet vs normal diet at } 3 \text { months } \\
(\mathrm{p}<0.0002) \text {, reduction in IBS-SSS } \\
\text { sustained after re-introduction of } \\
\text { FODMAPs at } 6 \text { months }\end{array}$ \\
\hline Hustoft [35] & 2017 & $\begin{array}{l}\text { Double blind } \\
\text { crossover RCT }\end{array}$ & 6 weeks & $\begin{array}{l}20 \text { patients with } \\
\text { IBS-D/IBS-M }\end{array}$ & $\begin{array}{l}\text { All participants received } \\
\text { placebo and low FODMAP } \\
\text { diet }\end{array}$ & $\begin{array}{l}\text { Significant improvement of all symptoms } \\
\text { following } 3 \text { weeks of low FODMAP diet } \\
\text { with mean reduction of IBS-SSS } 163.8\end{array}$ \\
\hline
\end{tabular}


a low FODMAP diet. A controlled cross-over feeding study demonstrated lower gastrointestinal symptom scores in patients given a low FODMAP diet, compared with an Australian diet and the participants' own diet [26]. Thirty patients with IBS, and 8 healthy controls were recruited for the study. Participants, who had not received dietary advice previously, received 3 weeks of a diet low in FODMAPs, or typical Australian diet, with a washout period of at least 3 weeks before crossover. The study demonstrated lower gastrointestinal symptom scores on a diet low in FODMAPs in comparison with an Australian diet ( $p$ $<0.001)$. Despite this statistically significant result, the benefits of the low FODMAP diet from this study have been debated. Krogsgaard et al. noted that participants on the control diet had a significant difference in the visual analogue scale (VAS) compared with the baseline diet (VAS 44.9 vs $36.0, \mathrm{p}<0.001$ ). It was suggested that this may have been attributed to the higher FODMAP content of the control diet versus the baseline diet, which may have led to favourable benefits of the low FODMAP diet seen in the study [27].

There have been several Randomized Controlled Trials (RCTs) published demonstrating the benefits of a low FODMAP diet in IBS, with Table I outlining some of these [26, 28-35]. The first meta-analysis of the low FODMAP diet in IBS, analyzing 6 RCTs and 16 non-randomized studies demonstrated its benefits. A statistically significant decrease in IBS symptom severity scores (IBS-SSS), IBS-quality of life score, symptom severity for abdominal pain, bloating and overall symptoms were demonstrated in both the RCTs and non-randomized studies [36]. Out of all the gastrointestinal symptoms reviewed in the meta-analysis, a low FODMAP diet led to the least improvement in symptoms of constipation, which may be attributed to the low fibre content of the diet [36], with the low FODMAP diet being shown to reduce small intestinal water [37]. Therefore, it is possible that patients with symptoms of IBS and constipation may need other adjuncts in addition to a low FODMAP diet to derive benefits. However, recently there has been evidence to suggest there is no significant difference in fibre content between a habitual diet and adapted low FODMAP diet in the longer term [38]. It has also been suggested that the Rome IV sub classification is of little use when assessing the effect of the low FODMAP diet, as the therapy is not directed at specific effects on bowel habits in view of its mechanism of action [39].

However, a systematic review focusing on the quality of nine RCTs of a low FODMAP diet in IBS suggested a high risk of bias in trials [40]. Concerns raised included small numbers of patients being used, with patients being recruited primarily from tertiary centers, as well as issues regarding blinding and choice of control group [40]. Another systematic review, where five studies of a low FODMAP diet in IBS were identified, deemed that the quality of evidence for the low FODMAP diet was only fair (Level II), with little evidence to support a recommendation for or against a low FODMAP diet in IBS (Grade C) on the basis of the studies reviewed [41].

With the emerging data about the role of a low FODMAP diet in IBS, a number of questions still remain. It is unclear how a low FODMAP diet compares to other dietary therapies, as there have been few head-to-head trials. A multi-centre RCT in Sweden [30] did not demonstrate a significant difference between traditional first-line dietary advice versus a low FODMAP diet. Potential limitations of this study have been suggested, questioning the adequacy of dietary advice given and the FODMAP composition used in the study [42]. Another trial in the United States demonstrated equal efficacy in composite end-points between low FODMAP diet and modified NICE guidelines in patients with IBS-D [31]. However, a recent meta-analysis, where 10 studies were analyzed, demonstrated a statistically significantly lower IBS severity scoring system (IBS-SSS) in those treated with a low FODMAP diet, in comparison with standard dietary advice $(p=0.002)$ [43]. Further research in this area is required before definitive conclusions can be made.

\section{Long-term outcomes}

The majority of data have focused on the role of the low FODMAP diet in IBS, with short term endpoints, and a lack of long term data. Long-term adherence to the low FODMAP diet appears to be good, with a prospective observational study demonstrating $75 \%$ adherence to an adapted low FODMAP diet after a median follow up of approximately 16 months, with $70 \%$ of patients satisfied with their symptoms [44]. This is also supported by other studies, with adherence reported as $77 \%$ (46/62 patients) in a retrospective study of IBS patients, where there was avoidance of short chain fructans and excess free fructose. Adherence in this study was assessed via telephone interview with a median follow up of 14 months [14]. A retrospective pilot study in 72 consecutive patients with IBD and concurrent functional symptoms demonstrated adherence in between $54 \%$ and $70 \%$, depending on the food group excluded, with a median follow up, via telephone interview, of 17 months [45].

There are concerns that patients may continue on a strict low FODMAP diet long-term, without adequate re-introduction of FODMAPs as tolerated. A retrospective study demonstrated that a minority of patients $(16 \%, 29 / 180)$ continued on a strict low FODMAP diet without re-introduction long-term (median 16 months) [46]. However, there are also data emerging, demonstrating the benefits of a low FODMAP diet in the longterm. A prospective questionnaire study $(n=103)$ following dietitian-led low FODMAP education demonstrated $57 \%$ of patients reporting relief of symptoms at long-term follow-up, with $82 \%$ continuing on an 'adapted' low FODMAP diet, with no compromise in terms of nutritional adequacy [38]. The longterm benefits of an 'adapted' low FODMAP diet have also been demonstrated in a recent parallel design study. Fifty patients with IBS were recruited through gastroenterology outpatient clinics, with 23 patients being commenced on a low FODMAP diet at baseline, followed by a re-challenge of foods at 3 months. A statistically significantly lower IBS-SSS was noted at 3 months in the low FODMAP group $(\mathrm{p}<0.0002)$, which was sustained at 6 months, despite re-challenge of FODMAPs [34]. These data suggest the efficacy of a low FODMAP diet in the long-term, with an 'adapted' low FODMAP diet.

\section{Potential risks of a low FODMAP diet}

Nutritional inadequacies are a potential concern using the low FODMAP approach. A RCT in 41 patients with IBS demonstrated a statistically significant reduction $(p=0.016)$ in 
Table II. Double Blind Placebo Controlled (DBPC) trial investigating the effect of a wheat free diet in IBS patients ( $\mathrm{n}=276$ )

\begin{tabular}{llllll}
\hline $\begin{array}{l}\text { Lead Author for } \\
\text { Study }\end{array}$ & Year & Study Design & $\begin{array}{l}\text { Study } \\
\text { Duration }\end{array}$ & $\begin{array}{l}\text { Total number of patients in } \\
\text { study }\end{array}$ & Intervention \\
\hline Carroccio [15] & 2012 & $\begin{array}{l}\text { Crossover } \\
\text { DBPC trial }\end{array}$ & 5 weeks & $\begin{array}{l}276 \text { patients with IBS } \\
\text { identified as having wheat } \\
\text { sensitivity }\end{array}$ & $\begin{array}{l}\text { All participants received } \\
\text { wheat or xylose (placebo) } \\
\text { capsules }\end{array}$ \\
\hline
\end{tabular}

calcium intake in those on a low FODMAP diet, compared with their habitual diet, after 4 weeks [28]. A significant reduction in energy intake has also been demonstrated in patients following a low FODMAP diet $(\mathrm{p}<0.001)$, in a RCT comparing the low FODMAP diet with traditional dietary advice [30]. This may be a potential concern in those at risk of undernutrition who continue to follow this diet in the long-term. However, there was also a significant reduction in energy intake in those following traditional dietary advice $(p=0.009)$, which suggests that this concern is not unique to a low FODMAP diet [30]. There is emerging data that utilization of an 'adapted' FODMAP diet may be nutritionally adequate, with a longterm follow-up postal questionnaire study demonstrating no significant difference in carbohydrate and calcium intake between an adapted low FODMAP diet and habitual diet at long term follow up, between 6 to 18 months [38].

There are also concerns about the effect of a low FODMAP diet on the gut microbiota. A RCT demonstrated a significant reduction $(\mathrm{p}<0.001)$ in luminal bifidobacteria following 4 weeks of a low FODMAP diet [28]. A single blind RCT in 27 patients with IBS, comparing the low FODMAP diet with a typical Australian diet, noted a reduction in total bacterial abundance [47]. A recent placebo-controlled study [33], in 104 patients with IBS, demonstrated that patients had a lower abundance of Bifidobacterium species in faecal samples on a low FODMAP diet in comparison with a sham diet, but higher levels when given a multi-species probiotic. Supplementation with probiotics could therefore potentially limit this, although long-term data are lacking.

\section{THE WHEAT FREE DIET}

Wheat avoidance has been reported to be common in the general population, with a cross-sectional population survey in Australian adults demonstrating that $10.6 \%$ (126/1184) were avoiding wheat [48].

A proportion of individuals presenting with IBS may have sensitivity to wheat. In a large retrospective study involving 920 patients fulfilling the Rome II criteria for IBS, 30\% (276/920) demonstrated wheat sensitivity or multiple food hypersensitivities (including wheat) [15] (Table II). Patients identified as wheat sensitive were on an elimination diet, but developed symptoms with wheat, given via capsules, using a double-blind placebo-controlled challenge. Significant increases in the VAS for overall symptoms, bloating, abdominal pain and stool consistency were demonstrated following the wheat challenge. To date, this remains the only crossover double-blind placebo-controlled (DBPC) trial assessing the WFD in IBS and has not been replicated.

Dramatic mucosal responses to wheat have been noted via confocal endomicroscopy in patients with IBS. A study in 36 patients demonstrated immediate and dramatic mucosal responses to several antigens, including wheat $(n=13)$, milk $(n=9)$, yeast $(n=6)$ and soy $(n=4)$ [49]. This interesting method may help identify patients who may benefit from a WFD, but further studies are required to assess this.

\section{Long-term outcomes}

Patients identified as being sensitive to wheat, in a large retrospective study [15], were assessed at follow up, for adherence to a strict WFD using structured questionnaires [50]. This prospective study involved 200 of the previous study cohort participants, with a median follow up of 99 months. Findings demonstrated that $74 \%(148 / 200)$ were still adhering to a strict wheat free diet at follow-up. Ten percent (21/200) were strictly avoiding wheat but consuming other glutencontaining foods, including barley and rye, with the other $64 \%$ $(127 / 200)$ on a strict GFD. Twenty-two patients from the study who were still on a WFD, consented to a repeat wheat challenge. It was noted that 20 of these 22 patients still reacted to wheat. This highlights that wheat sensitivity is likely to be persistent.

\section{Potential risks of a WFD}

There is little data currently on the risks of a WFD. Patients consuming a WFD commonly commence a GFD [50], and it could be inferred that the risks are likely to be similar to those of a GFD. These risks include lower intakes of magnesium, iron, zinc, manganese and folate, noted from studies in coeliac disease [51]. Due to the lack of data, studies are required in this area to be able to elucidate the quantifiable risks.

\section{THE GLUTEN FREE DIET}

The concept of patients presenting with symptoms after the ingestion of gluten without a diagnosis of coeliac disease has been described as early as the 1980s [52]. With regards to the mechanism of induction of symptoms with gluten, it has been suggested that gluten proteins may be insufficiently degraded by proteases, leading to undigested peptides with an innate immune response, which may trigger gastrointestinal symptoms. However, further research is needed to elucidate the mechanisms [53].

Recent research has assessed the role of a GFD in patients presenting with IBS. A RCT of a GFD vs gluten containing diet was performed in 45 patients with IBS-D over 4 weeks, which demonstrated that patients had increased bowel movements on a gluten containing diet $(\mathrm{p}=0.04)$, as well as the gluten containing diet having a greater effect on bowel movements in HLA-DQ2/8 positive, compared with negative, patients $(\mathrm{p}=0.019)$ [54]. An increased bowel permeability in HLADQ2/8 positive compared with negative patients $(\mathrm{p}=0.018$ ) was also shown in this study, demonstrating that gluten may alter intestinal barrier function in patients with IBS-D, particularly those who are HLA-DQ2/8 positive [54]. 
The benefit of a GFD in patients with IBS-D has also been shown in other studies. A prospective study of 41 patients with IBS-D, demonstrated a significant $(\mathrm{p}<0.001)$ reduction in mean IBS-SSS from 286 to 131 after 6 weeks of a GFD, following evaluation by a dietitian, with similar reductions in both HLA-DQ2/8 positive and negative subjects [55]. Twenty-one out of 29 subjects with a clinical response $(72 \%)$ were still on a GFD 18 months after the study, and planned to continue longterm, with similar anthropometric and biochemical features compared with baseline [55].

There have been several DBPC trials assessing the effect of a GFD in IBS, as summarized in Table III [15, 56-59]. A study in 34 patients with IBS, in whom coeliac disease had been excluded, who had been symptomatically controlled on a GFD, received gluten or placebo in the form of bread slices and one muffin per day for up to 6 weeks. Worsening of overall symptoms, pain, bloating, stool satisfaction and tiredness following the introduction of gluten versus placebo was noted within 1 week, thereby demonstrating the deleterious effect of gluten in this patient population [56]

Interestingly, the same group later published data failing to demonstrate the effect of gluten on induction of symptoms in patients with IBS that self-reported an improvement on a GFD, following the initiation of a low FODMAP diet. A double-blind crossover trial was performed in 37 subjects, having had coeliac disease excluded. Participants were initially placed on a twoweek low FODMAP diet, followed by random allocation to a high-gluten, low-gluten or control diet for 1 week, followed by a washout period of at least 2 weeks. The authors concluded that there was no additive effect of a GFD in this group of patients following implementation of a low FODMAP diet. However, it must be noted that patients in the study had a high VAS at baseline, which may not be truly representative of this patient group [57]. Secondly, due to the design of this study there may have been an anticipatory nocebo response, as patients were knowingly going to receive high gluten, low gluten or placebo challenges. An interesting observation was that participants continued to follow the GFD following completion of the study [60]. This may provide support for the ease of implementation of a GFD, with long term adherence to a GFD being shown at $64 \%$ at 12 months, in a recent study of 35 patients with IBS-D or IBS-M, in those who had responded symptomatically [61].

There have been other trials demonstrating the benefit of a GFD in IBS. A trial in 148 patients with IBS, of whom 72 patients completed the study, evaluated the effect of a GFD in patients with IBS. After patients had been initially commenced on a GFD, a statistically significantly lower symptom control was noted following re-introduction of gluten vs placebo $(p<0.001)$, showing that patients are likely to be sensitive to gluten [58]. In a further trial, 60 Indian patients with IBS, who had responded a GFD for 4 weeks, were allocated to either placebo or gluten for 4 weeks, via bread (gluten free vs gluten containing). Significant worsening of symptoms was noted in patients who were re-challenged with gluten in comparison with a placebo $(\mathrm{p}<0.05)$ [59].

\section{Potential risks of GFD}

Despite the benefits of a GFD in IBS, as described in the studies above, there are still some unanswered questions. There are concerns with regards to nutrient intake with a GFD. Data obtained from patients with coeliac disease, who also maintain a GFD, highlight this potential concern. A study, where prospective validated 5-day food diaries were analyzed in 139 patients with coeliac disease, demonstrated

Table III. Summary of Double Blind Placebo Controlled (DBPC) trials investigating the effect of a gluten free diet in IBS patients ( $\mathrm{n}=203$ )

\begin{tabular}{|c|c|c|c|c|c|c|}
\hline $\begin{array}{l}\text { Lead Author for } \\
\text { Study }\end{array}$ & Year & Study Design & Study Duration & $\begin{array}{l}\text { Total number of } \\
\text { patients in study }\end{array}$ & Intervention & Outcome \\
\hline Biesiekierski [56] & 2011 & DBPC trial & 6 weeks & $\begin{array}{l}34 \text { patients with IBS } \\
\text { symptomatically } \\
\text { controlled on GFD }\end{array}$ & $\begin{array}{l}\text { Placebo } n=15 \\
\text { Gluten } n=19\end{array}$ & $\begin{array}{l}\text { Worsening of overall } \\
\text { symptoms on VAS } \\
(\mathrm{p}=0.047) \text {, as well } \\
\text { as pain }(\mathrm{p}=0.016) \text {, } \\
\text { bloating }(\mathrm{p}=0.016) \text {, stool } \\
\text { consistency }(\mathrm{p}=0.024) \\
\text { and tiredness }(\mathrm{p}=0.001) \\
\text { following gluten } \\
\text { introduction }\end{array}$ \\
\hline Carroccio [15] & 2012 & $\begin{array}{l}\text { Crossover DBPC } \\
\text { trial }\end{array}$ & 5 weeks & $\begin{array}{l}276 \text { patients with IBS } \\
\text { identified as having } \\
\text { wheat sensitivity }\end{array}$ & $\begin{array}{l}\text { All participants } \\
\text { received wheat or } \\
\text { xylose (placebo) } \\
\text { capsules }\end{array}$ & $\begin{array}{l}\text { Increase in overall } \\
\text { symptoms following } \\
\text { introduction of wheat } \\
(p<0.0001)\end{array}$ \\
\hline Biesiekierski [57] & 2013 & $\begin{array}{l}\text { Crossover DBPC } \\
\text { trial }\end{array}$ & $\begin{array}{l}2 \text { week run in of low } \\
\text { FODMAPs then } 1 \text { week } \\
\text { of high-gluten, low } \\
\text { gluten, or placebo for } 1 \\
\text { week followed by } 2 \text { week } \\
\text { washout period }\end{array}$ & $\begin{array}{l}37 \text { patients with IBS } \\
\text { and NCGS }\end{array}$ & $\begin{array}{l}\text { All participants } \\
\text { received high } \\
\text { gluten, low gluten or } \\
\text { placebo }\end{array}$ & $\begin{array}{l}\text { No effect of gluten on GI } \\
\text { symptoms }\end{array}$ \\
\hline $\begin{array}{l}\text { Shahbazkhani } \\
{[58]}\end{array}$ & 2015 & DBPC trial & 6 weeks & $\begin{array}{l}72 \text { patients with IBS } \\
\text { on GFD }\end{array}$ & $\begin{array}{l}\text { Placebo } n=37 \\
\text { Gluten } n=35\end{array}$ & $\begin{array}{l}\text { Statistically significant } \\
\text { worsening of symptoms in } \\
\text { gluten-containing group } \\
\text { versus placebo }(\mathrm{p}<0.001)\end{array}$ \\
\hline Zanwar [59] & 2016 & DBPC trial & 4 weeks & $\begin{array}{l}60 \text { patients with IBS } \\
\text { who responded to } \\
\text { GFD }\end{array}$ & $\begin{array}{l}\text { Placebo } n=30 \\
\text { Gluten } n=30\end{array}$ & $\begin{array}{l}\text { Worsening of symptoms } \\
\text { following intake of gluten } \\
(\mathrm{p}<0.05)\end{array}$ \\
\hline
\end{tabular}


lower intakes of magnesium, iron, zinc, manganese and folate. Also there was a higher proportion of carbohydrate intake from non-milk extrinsic sugars and low intake of non-starch polysaccharides [51].

The effect on the gut microbiota also requires further exploration, with studies demonstrating an alteration in the composition of the gut microbiota on a GFD. A study in 10 healthy subjects on a GFD demonstrated reductions in proportions of Bifidobacterium, Clostridium lituseburense and Faecalibacterium prausnitzii after 4 weeks, analyzed via fluorescence in-situ hybridization [62]. A study in 21 healthy individuals who followed a GFD for 4 weeks demonstrated changes in gut microbiota, including a decrease in Veillonellaceae, Ruminococcus bromii, and Roseburia faecis, with an increase in Victivallaceae, Clostridiaceae, ML615J-28, Slackia and Coriobacteriaceae [63].

Cost of implementation of a GFD are also a potential concern [64]. A study, assessing the financial cost of gluten free food in Sheffield, UK, demonstrated that these were at least 4 times more expensive than gluten containing alternatives $(\mathrm{p}<0.0001)$, but availability was good in quality supermarkets, stocking a median of 22 items [64].

\section{DISCUSSION}

There are now several heterogeneous randomized trials in IBS evaluating the low FODMAP diet, WFD and GFD (total number of patients recruited from randomized trials reviewed: $\mathrm{n}=580$ low FODMAP diet [female, $\mathrm{n}=430$ ], $\mathrm{n}=203$ GFD [female, $n=139$ ], $n=276$ WFD [female, $n=215$ ]), with variable evidence for the use of all three diets. There was no significant difference in the gender of patients recruited for both the low FODMAP and GFD randomized studies $(\mathrm{p}=0.12)$, as assessed by Fischer's exact test. The response rate to a low FODMAP diet has been recorded between $50 \%$ to $76 \%$ in the literature $[28,30$, $44,65]$, with a response rate to a GFD reported between $34 \%$ to $71 \%[55,61]$. In IBS patients identified as wheat sensitive, reported as $30 \%$ in the literature [15], response to a wheat or GFD has been demonstrated to be as high as $98 \%$ [50]. The evidence to date suggests that one diet alone is not effective for all patients with IBS, reinforcing the underlying heterogeneity of the condition.

It is likely that there is significant overlap between these dietary therapies, and they could be described as dietary 'cousins. For example, controversy remains with regards to which component of wheat leads to the induction of symptoms in patients presenting with IBS [66]. There are questions as to whether gluten is the causal agent in triggering symptoms in IBS, or fructans, a type of FODMAP. A recent double-blind cross over challenge of 59 participants who had self-instituted a GFD demonstrated an increase in overall gastrointestinal symptoms in participants consuming fructans rather than gluten $(p=0.049)$ [67]. Other components in wheat, including alpha-amylase trypsin inhibitors (ATIs) and wheat germ agglutinins are also potential causal agents [68]. Regardless of the mechanism, there appears to be evidence for the use of all these diets in clinical practice [15]. Table IV outlines a comparison of these therapies.

We would suggest that dietary advice for these therapies should be delivered by dietitians with a specialist interest in IBS, on the basis of the evidence base for the use of these diets being derived from dietitian-led studies, with this approach being supported by other reviews [69]. The delivery of a low FODMAP diet, WFD and GFD could lead to a strain on existing resources, but could be achieved through different methods, such as group-based sessions rather than one-toone education. This is supported by a large study $(n=364)$ assessing dietitian-led group education vs traditional oneto-one education for a low FODMAP diet [70]. This study demonstrated no difference in patient satisfaction or difference in decrease in symptom severity following dietary advice in group education vs one-to-one education [70]. Webinars

Table IV. Comparison of low FODMAP, wheat free and gluten free diet in IBS

\begin{tabular}{|c|c|c|c|}
\hline & Low FODMAP diet & Wheat Free Diet & Gluten Free Diet \\
\hline \multirow[t]{4}{*}{ Advantages of diet } & Increasing public awareness of diet & $\begin{array}{l}\text { Large proportion of patients with IBS } \\
\text { sensitive to wheat }(30 \%) \text { so likely to } \\
\text { beneficial }[15]\end{array}$ & Well known diet to public [72] \\
\hline & $\begin{array}{l}\text { Re-introduction of FODMAPs can be } \\
\text { tailored to patients' symptoms }\end{array}$ & Restriction of one food group & Easy to implement \\
\hline & & & $\begin{array}{l}\text { Good availability of diet in } \\
\text { supermarkets in UK [64] }\end{array}$ \\
\hline & & & Restriction of one food group \\
\hline \multirow[t]{5}{*}{ Concerns of diet } & Restrictive diet in initial phase [21] & Causal agent unknown [66] & Costly to implement [64] \\
\hline & $\begin{array}{l}\text { Reduction in calorie and calcium intake } \\
\text { reported [28] }\end{array}$ & Insufficient data on risks & $\begin{array}{l}\text { Lower intake of nutrients including } \\
\text { magnesium, iron, zinc, manganese } \\
\text { and folate reported [51] }\end{array}$ \\
\hline & $\begin{array}{l}\text { Unclear efficacy in comparison to other } \\
\text { dietary therapies }[30,31]\end{array}$ & & $\begin{array}{l}\text { Reduction in beneficial gut bacteria } \\
\text { populations reported [62] }\end{array}$ \\
\hline & Costly to implement [38] & & Poor palatability [73] \\
\hline & $\begin{array}{l}\text { Reduction in potentially beneficial gut } \\
\text { bacteria reported [28] }\end{array}$ & & \\
\hline Adherence & $\begin{array}{l}\text { Adherence reported at } 75-77 \text { percent in } \\
\text { literature }[14,44]\end{array}$ & $\begin{array}{l}\text { Adherence reported at } 74 \text { percent in } \\
\text { literature [50] }\end{array}$ & $\begin{array}{l}\text { Adherence reported at } 64 \text { percent in } \\
\text { literature [61] }\end{array}$ \\
\hline
\end{tabular}


could also potentially be used to help disseminate dietary advice, with recent data suggesting that webinars delivered by dietitians may improve confidence in patients managing IBS symptoms [71].

\section{CONCLUSION}

There are currently no head-to-head trials evaluating the low FODMAP diet, WFD and GFD in IBS. There is evidence for the use of all three diets in IBS, but questions still remain, including concerns on the nutritional adequacy of all the diets, as well as the effects on the gut microbiota. Further long-term efficacy data are required. The decision-making process for using each individual diet should be directed by a detailed history by a dietitian, involving the patient in the process.

\section{CONSENSUS HIGHLIGHTS}

1. The low FODMAP diet, WFD and GFD all have variable evidence for use in IBS.

2. The choice of dietary therapy should be tailored to the individual patient.

3. Dietary advice for these diets should be delivered by a dietitian with a specialist interest in IBS.

4. Concerns for all three diets still exist, with further longterm efficacy data required.

Conflicts of interest: No authors have declared conflicts of interest.

Authors' contributions: All co-authors actively participated in the round table meeting discussion that formed the basis for drafting this manuscript, except Professor Alexander Ford, who was not available for the round table meeting discussion, but was supplied with the information post meeting. All authors helped critically revise the text and approved final draft submission.

Acknowledgements: The round table meeting discussion in Sheffield was funded by the Dr. Schär Institute, Merano, Italy. We wish to express our gratitude to Fabiana Saorin, Melissa Wilson and Katie Kennedy from the Dr. Schär Institute for taking care of the organization of the meeting. All work leading to the development of this article was independent of this funding.

\section{REFERENCES}

1. Lovell RM, Ford AC. Global prevalence of and risk factors for irritable bowel syndrome: a meta-analysis. Clin Gastroenterol Hepatol 2012;10:712-721.e4. doi:10.1016/j.cgh.2012.02.029

2. Schmulson MJ, Drossman DA. What Is New in Rome IV. J Neurogastroenterol Motil 2017;23:151-163. doi:10.5056/jnm16214

3. Portincasa P, Bonfrate L, de Bari O, Lembo A, Ballou S. Irritable bowe syndrome and diet. Gastroenterol Rep (Oxf) 2017;5:11-19. doi:10.1093/ gastro/gow047

4. Akehurst RL, Brazier JE, Mathers N, et al. Health-related quality of life and cost impact of irritable bowel syndrome in a UK primary care setting. Pharmacoeconomics 2002;20:455-462. doi:10.2165/00019053200220070-00003
5. Simrén M, Månsson A, Langkilde AM, et al. Food-related gastrointestinal symptoms in the irritable bowel syndrome. Digestion 2001;63:108-115. doi: $10.1159 / 000051878$

6. Monsbakken KW, Vandvik PO, Farup PG. Perceived food intolerance in subjects with irritable bowel syndrome etiology, prevalence and consequences. Eur J Clin Nutr 2006;60:667-672. doi:10.1038/ sj.ejcn.1602367

7. Böh L, Störsrud S, Simrén M. Nutrient intake in patients with irritable bowel syndrome compared with the general population. Neurogastroenterol Motil 2013;25:23-30.e1. doi:10.1111/nmo.12001

8. Jones VA, McLaughlan P, Shorthouse M, Workman E, Hunter JO. Food intolerance: a major factor in the pathogenesis of irritable bowel syndrome. Lancet 1982;2:1115-1117. doi:10.1016/S01406736(82)92782-9

9. Nanda R, James R, Smith H, Dudley CR, Jewell DP. Food intolerance and the irritable bowel syndrome. Gut 1989;30:1099-1104. doi:10.1136/ gut.30.8.1099

10. Park MI, Camilleri M. Is there a role of food allergy in irritable bowel syndrome and functional dyspepsia? A systematic review. Neurogastroenterol Motil 2006;18:595-607. doi:10.1111/j.13652982.2005.00745.x

11. Parker TJ, Naylor SJ, Riordan AM, Hunter JO. Management of patients with food intolerance in irritable bowel syndrome: the development and use of an exclusion diet. J Hum Nutr Diet 1995;8:159-166. doi:10.1111/ j.1365-277X.1995.tb00308.x

12. McKenzie YA, Bowyer RK, Leach H, et al. British Dietetic Association systematic review and evidence-based practice guidelines for the dietary management of irritable bowel syndrome in adults (2016 update). J Hum Nutr Diet 2016;29:549-575. doi:10.1111/jhn.12385

13. National Institute for Health and Care Excellence. Irritable bowel syndrome in adults: diagnosis and management. Clinical Guideline [CG61]. Published: February 2008. Last updated: April 2017. Available at: https://www.nice.org.uk/guidance/cg61

14. Shepherd SJ, Gibson PR. Fructose malabsorption and symptoms of irritable bowel syndrome: guidelines for effective dietary management. J Am Diet Assoc 2006;106:1631-1639. doi:10.1016/j.jada.2006.07.010

15. Carroccio A, Mansueto P, Iacono G, et al. Non-celiac wheat sensitivity diagnosed by double-blind placebo-controlled challenge: exploring a new clinical entity. Am J Gastroenterol 2012;107:1898-1906. doi:10.1038/ajg.2012.236

16. Wahnschaffe U, Ullrich R, Riecken EO, Schulzke JD. Celiac diseaselike abnormalities in a subgroup of patients with irritable bowel syndrome. Gastroenterology 2001;121:1329-1338. doi:10.1053/ gast.2001.29572

17. Moayyedi P, Quigley EM, Lacy BE, et al. The effect of fiber supplementation on irritable bowel syndrome: a systematic review and meta-analysis. Am J Gastroenterol 2014;109:1367-1374. doi:10.1038/ ajg.2014.195

18. Murray K, Wilkinson-Smith V, Hoad C, et al. Differential effects of FODMAPs (fermentable oligo-, di-, mono-saccharides and polyols) on small and large intestinal contents in healthy subjects shown by MRI. Am J Gastroenterol 2014;109:110-119. doi:10.1038/ajg.2013.386

19. Spiller R. How do FODMAPs work? J Gastroenterol Hepatol 2017;32 Suppl 1:36-39. doi:10.1111/jgh.13694

20. Major G, Pritchard S, Murray K, et al. Colon Hypersensitivity to Distension, Rather Than Excessive Gas Production, Produces Carbohydrate-Related Symptoms in Individuals With Irritable Bowel Syndrome. Gastroenterology 2017;152:124-133.e2. doi:10.1053/j. gastro.2016.09.062 
21. Whelan K, Martin LD, Staudacher HM, Lomer MCE. The low FODMAP diet in the management of irritable bowel syndrome: an evidence-based review of FODMAP restriction, reintroduction and personalisation in clinical practice. J Hum Nutr Diet 2018;31:239-255. doi:10.1111/ jhn. 12530

22. Halmos EP. When the low FODMAP diet does not work. J Gastroenterol Hepatol 2017;32 Suppl 1:69-72. doi:10.1111/jgh.13701

23. Gibson PR, Shepherd SJ. Personal view: food for thought--western lifestyle and susceptibility to Crohn's disease. The FODMAP hypothesis. Aliment Pharmacol Ther 2005;21:1399-1409. doi:10.1111/j.13652036.2005.02506.x

24. Gibson PR, Shepherd SJ. Evidence-based dietary management of functional gastrointestinal symptoms: The FODMAP approach. J Gastroenterol Hepatol 2010;25:252-258. doi:10.1111/j.14401746.2009.06149.x

25. Shepherd SJ, Parker FC, Muir JG, Gibson PR. Dietary triggers of abdominal symptoms in patients with irritable bowel syndrome: randomized placebo-controlled evidence. Clin Gastroenterol Hepatol 2008;6:765-771. doi:10.1016/j.cgh.2008.02.058

26. Halmos EP, Power VA, Shepherd SJ, Gibson PR, Muir JG. A diet low in FODMAPs reduces symptoms of irritable bowel syndrome. Gastroenterology 2014;146:67-75.e5. doi:10.1053/j.gastro.2013.09.046

27. Krogsgaard LR, Lyngesen M, Bytzer P. Letter: bias in clinical trials of the symptomatic effects of the low FODMAP diet for irritable bowel syndrome-getting the facts right. Authors' reply. Aliment Pharmacol Ther 2017;46:386-387. doi:10.1111/apt.14165

28. Staudacher HM, Lomer MC, Anderson JL, et al. Fermentable carbohydrate restriction reduces luminal bifidobacteria and gastrointestinal symptoms in patients with irritable bowel syndrome. J Nutr 2012;142:1510-1518. doi:10.3945/jn.112.159285

29. Pedersen N, Andersen NN, Végh Z, et al. Ehealth: low FODMAP diet vs Lactobacillus rhamnosus GG in irritable bowel syndrome. World J Gastroenterol 2014;20:16215-16226. doi:10.3748/wjg.v20.i43.16215

30. Böhn L, Störsrud S, Liljebo T, et al. Diet low in FODMAPs reduces symptoms of irritable bowel syndrome as well as traditional dietary advice: a randomized controlled trial. Gastroenterology 2015;149:13991407.e2. doi:10.1053/j.gastro.2015.07.054

31. Eswaran SL, Chey WD, Han-Markey T, Ball S, Jackson K. A Randomized Controlled Trial Comparing the Low FODMAP Diet vs. Modified NICE Guidelines in US Adults with IBS-D. Am J Gastroenterol 2016;111:18241832. doi:10.1038/ajg.2016.434

32. McIntosh K, Reed DE, Schneider T, et al. FODMAPs alter symptoms and the metabolome of patients with IBS: a randomised controlled trial. Gut 2017;66:1241-1251. doi:10.1136/gutjnl-2015-311339

33. Staudacher HM, Lomer MCE, Farquharson FM, et al. Diet Low in FODMAPs Reduces Symptoms in Patients with Irritable Bowel Syndrome and Probiotic Restores Bifidobacterium Species: a Randomized Controlled Trial. Gastroenterology 2017;153:936-947. doi:10.1053/j.gastro.2017.06.010

34. Harvie RM, Chisholm AW, Bisanz JE, et al. Long-term irritable bowel syndrome symptom control with reintroduction of selected FODMAPs. World J Gastroenterol 2017;23:4632-4643. doi:10.3748/wjg.v23.i25.4632

35. Hustoft TN, Hausken T, Ystad SO, et al. Effects of varying dietary content of fermentable short-chain carbohydrates on symptoms, fecal microenvironment, and cytokine profiles in patients with irritable bowel syndrome. Neurogastroenterol Motil 2017;29. doi:10.1111/nmo.12969

36. Marsh A, Eslick EM, Eslick GD. Does a diet low in FODMAPs reduce symptoms associated with functional gastrointestinal disorders?
A comprehensive systematic review and meta-analysis. Eur J Nutr 2016;55:897-906. doi:10.1007/s00394-015-0922-1

37. Barrett JS, Gearry RB, Muir JG, et al. Dietary poorly absorbed, shortchain carbohydrates increase delivery of water and fermentable substrates to the proximal colon. Aliment Pharmacol Ther 2010;31:874882. doi:10.1111/j.1365-2036.2010.04237.x

38. O'Keeffe M, Jansen C, Martin L, et al. Long-term impact of the lowFODMAP diet on gastrointestinal symptoms, dietary intake, patient acceptability, and healthcare utilization in irritable bowel syndrome. Neurogastroenterol Motil 2018;30. doi:10.1111/nmo.13154

39. Gibson PR. The evidence base for efficacy of the low FODMAP diet in irritable bowel syndrome: is it ready for prime time as a first-line therapy? J Gastroenterol Hepatol 2017;32 Suppl 1:32-35. doi:10.1111/ jgh.13693

40. Krogsgaard LR, Lyngesen M, Bytzer P. Systematic review: quality of trials on the symptomatic effects of the low FODMAP diet for irritable bowel syndrome. Aliment Pharmacol Ther 2017;45:1506-1513. doi:10.1111/ apt.14065

41. Rao SS, Yu S, Fedewa A. Systematic review: dietary fibre and FODMAPrestricted diet in the management of constipation and irritable bowel syndrome. Aliment Pharmacol Ther 2015;41:1256-1270. doi:10.1111/ apt.13167

42. Gibson PR, Varney JE, Muir JG. Diet Therapy for Irritable Bowel Syndrome: Is a Diet Low in FODMAPS Really Similar in Efficacy to Traditional Dietary Advice? Gastroenterology 2016;150:1046-1047. doi:10.1053/j.gastro.2015.10.053

43. Varjú P, Farkas N, Hegyi P, et al. Low fermentable oligosaccharides, disaccharides, monosaccharides and polyols (FODMAP) diet improves symptoms in adults suffering from irritable bowel syndrome (IBS) compared to standard IBS diet: A meta-analysis of clinical studies. PLoS One 2017;12:e0182942. doi:10.1371/journal.pone.0182942

44. de Roest RH, Dobbs BR, Chapman BA, et al. The low FODMAP diet improves gastrointestinal symptoms in patients with irritable bowel syndrome: a prospective study. Int J Clin Pract 2013;67:895-903. doi: 10.1111/ijcp.12128

45. Gearry RB, Irving PM, Barrett JS, Nathan DM, Shepherd SJ, Gibson PR. Reduction of dietary poorly absorbed short-chain carbohydrates (FODMAPs) improves abdominal symptoms in patients with inflammatory bowel disease-a pilot study. J Crohns Colitis 2009;3:8-14. doi:10.1016/j.crohns.2008.09.004

46. Maagaard L, Ankersen DV, Végh Z, et al. Follow-up of patients with functional bowel symptoms treated with a low FODMAP diet. World J Gastroenterol 2016;22:4009-4019. doi:10.3748/wjg.v22.i15.4009

47. Halmos EP, Christophersen CT, Bird AR, Shepherd SJ, Gibson PR, Muir JG. Diets that differ in their FODMAP content alter the colonic luminal microenvironment. Gut 2015;64:93-100. doi:10.1136/ gutjnl-2014-307264

48. Golley S, Corsini N, Topping D, Morell M, Mohr P. Motivations for avoiding wheat consumption in Australia: results from a population survey. Public Health Nutr 2015;18:490-499. doi:10.1017/ S1368980014000652

49. Fritscher-Ravens A, Schuppan D, Ellrichmann M, et al. Confocal endomicroscopy shows food-associated changes in the intestinal mucosa of patients with irritable bowel syndrome. Gastroenterology 2014;147:1012-1020.e4. doi:10.1053/j.gastro.2014.07.046

50. Carroccio A, D’Alcamo A, Iacono G, et al. Persistence of Nonceliac Wheat Sensitivity, Based on Long-term Follow-up. Gastroenterology 2017;153:56-58.e3. doi:10.1053/j.gastro.2017.03.034 
51. Wild D, Robins GG, Burley VJ, Howdle PD. Evidence of high sugar intake, and low fibre and mineral intake, in the gluten-free diet. Aliment Pharmacol Ther 2010;32:573-581. doi:10.1111/j.1365. 2036.2010.04386.x

52. Cooper BT, Holmes GK, Ferguson R, Thompson RA, Allan RN, Cooke WT. Gluten-sensitive diarrhea without evidence of celiac disease Gastroenterology 1980;79:801-806.

53. Volta U, Pinto-Sanchez MI, Boschetti E, Caio G, De Giorgio R, Verdu EF. Dietary Triggers in Irritable Bowel Syndrome: Is There a Role for Gluten? J Neurogastroenterol Motil 2016;22:547-557. doi:10.5056/ jnm 16069

54. Vazquez-Roque MI, Camilleri M, Smyrk T, et al. A controlled trial of gluten-free diet in patients with irritable bowel syndrome-diarrhea: effects on bowel frequency and intestinal function. Gastroenterology 2013;144:903-911.e3. doi:10.1053/j.gastro.2013.01.049

55. Aziz I, Trott N, Briggs R, North JR, Hadjivassiliou M, Sanders DS Efficacy of a Gluten-Free Diet in Subjects With Irritable Bowel Syndrome-Diarrhea Unaware of Their HLA-DQ2/8 Genotype. Clin Gastroenterol Hepatol 2016;14:696-703.e1. doi:10.1016/j. cgh.2015.12.031

56. Biesiekierski JR, Newnham ED, Irving PM, et al. Gluten causes gastrointestinal symptoms in subjects without celiac disease: a double-blind randomized placebo-controlled trial. Am J Gastroenterol 2011;106:508-514. doi:10.1038/ajg.2010.487

57. Biesiekierski JR, Peters SL, Newnham ED, Rosella O, Muir JG, Gibson PR. No effects of gluten in patients with self-reported non-celiac gluten sensitivity after dietary reduction of fermentable, poorly absorbed, short-chain carbohydrates. Gastroenterology 2013;145:320-328.e1-3. doi:10.1053/j.gastro.2013.04.051

58. Shahbazkhani B, Sadeghi A, Malekzadeh R, et al. Non-Celiac Gluten Sensitivity Has Narrowed the Spectrum of Irritable Bowel Syndrome: A Double-Blind Randomized Placebo-Controlled Trial. Nutrients 2015;7:4542-4554. doi:10.3390/nu7064542

59. Zanwar VG, Pawar SV, Gambhire PA, et al. Symptomatic improvement with gluten restriction in irritable bowel syndrome: a prospective, randomized, double blinded placebo controlled trial. Intest Res 2016;14:343-350. doi:10.5217/ir.2016.14.4.343

60. Peters SL, Biesiekierski JR, Yelland GW, Muir JG, Gibson PR. Randomised clinical trial: gluten may cause depression in subjects with non-coeliac gluten sensitivity - an exploratory clinical study. Aliment Pharmacol Ther 2014;39:1104-1112. doi:10.1111/apt.12730

61. Barmeyer C, Schumann M, Meyer T, et al. Long-term response to gluten-free diet as evidence for non-celiac wheat sensitivity in one third of patients with diarrhea-dominant and mixed-type irritable bowel syndrome. Int J Colorectal Dis 2017;32:29-39. doi:10.1007/s00384-0162663-x

62. De Palma G, Nadal I, Collado MC, Sanz Y. Effects of a gluten-free diet on gut microbiota and immune function in healthy adult human subjects. Br J Nutr 2009;102:1154-1160. doi:10.1017/S0007114509371767

63. Bonder MJ, Tigchelaar EF, Cai X, et al. The influence of a short-term gluten-free diet on the human gut microbiome. Genome Med 2016;8:45. doi:10.1186/s13073-016-0295-y

64. Burden M, Mooney PD, Blanshard RJ, White WL, Cambray-Deakin DR, Sanders DS. Cost and availability of gluten-free food in the UK: in store and online. Postgrad Med J 2015;91:622-626. doi:10.1136/ postgradmedj-2015-133395

65. Tuck CJ, Muir JG, Barrett JS, Gibson PR. Fermentable oligosaccharides, disaccharides, monosaccharides and polyols: role in irritable bowel syndrome. Expert Rev Gastroenterol Hepatol 2014;8:819-834. doi:10. 1586/17474124.2014.917956

66. De Giorgio R, Volta U, Gibson PR. Sensitivity to wheat, gluten and FODMAPs in IBS: facts or fiction? Gut 2016;65:169-178. doi:10.1136/ gutjnl-2015-309757

67. Skodje GI, Sarna VK, Minelle IH, et al. Fructan, Rather Than Gluten, Induces Symptoms in Patients With Self-reported Non-celiac Gluten Sensitivity. Gastroenterology 2018;154:529-539.e2. doi:10.1053/j. gastro.2017.10.040

68. Aziz I, Hadjivassiliou M, Sanders DS. The spectrum of noncoeliac gluten sensitivity. Nat Rev Gastroenterol Hepatol 2015;12:516-526. doi:10.1038/nrgastro.2015.107

69. O'Keeffe M, Lomer MC. Who should deliver the low FODMAP diet and what educational methods are optimal: a review. J Gastroenterol Hepatol 2017;32 Suppl 1:23-26. doi:10.1111/jgh.13690

70. Whigham L, Joyce T, Harper G, et al. Clinical effectiveness and economic costs of group versus one-to-one education for short-chain fermentable carbohydrate restriction (low FODMAP diet) in the management of irritable bowel syndrome. J Hum Nutr Diet 2015;28:687-696. doi:10.1111/jhn.12318

71. Williams M. Somerset IBS webinars: Are webinars the way forward for NHS patient education? 2018.Available at: http://issuu.com/ mariannewilliams/docs

72. Aziz I, Karajeh MA, Zilkha J, Tubman E, Fowles C, Sanders DS. Change in awareness of gluten-related disorders among chefs and the general public in the UK: a 10-year follow-up study. Eur J Gastroenterol Hepatol 2014;26:1228-1233. doi:10.1097/MEG.0000000000000166

73. Pietzak MM. Follow-up of patients with celiac disease: achieving compliance with treatment. Gastroenterology 2005;128(4 Suppl 1):S135-S141. doi:10.1053/j.gastro.2005.02.025 